\title{
Correlation between Children's Pragmatic Language Checklist and Conversation Observations
}

\author{
So Jung Oh \\ Department of Communication Disorders, Tongmyong University, Busan, Korea
}

Correspondence: So Jung Oh, PhD Department of Communication Disorders, Tongmyong University, 428 Sinseon-ro, Nam-gu, Busan 48520, Korea

Tel: +82-51-629-2132

Fax: +82-51-629-2019

E-mail: sjoh@tu.ac.kr

Received: January 26, 2018

Revised: February 27, 2018

Accepted: February 27, 2018

This work was supported by the National Research Foundation of Korea (NRF) Grant funded by the Korean Government (No. NRF-2014S1A5A8018878).
Objectives: This study aimed to investigate the relationship between the Children's Pragmatic Language Checklist (CPLC) and communication skill in actual conversation to examine the clinical validity of CPLC and to see whether it reflects communication skills in everyday life. Methods: Fourteen 1-4 grade school-age children with typical language development and fourteen age-matched children with pragmatic language problems participated in conversation sampling; their parents filled out the CPLC questionnaire. Conversation observation measures were matched with CPLC subarea. Differences between the two groups were statistically examined using two independent sample $t$-tests; the relationship between CPLC scores and conversation observation measures was measured by Pearson's correlation coefficient. Results: The $t$-test analysis revealed that group differences were more salient in CPLC scores than conversation observation measures. The correlations coefficient between CPLC scores and some conversation sample measures were statistically significant (mostly .40-.60), implying moderate correlation. Topic management measures, including appropriate/inappropriate topic initiation and maintenance rate, were mostly correlated to CPLC total score and subscores. Conclusion: CPLC can reflect communication skills in real conversation, but it is not clear which CPLC scores are related to certain measures. As discussed in previous studies, pragmatic assessment procedures may vary in degrees of correlation, which can create group difference among clinical groups. The results were discussed in terms of pragmatic skills assessment in clinical practice.

Keywords: Pragmatic language, Checklist, Conversation skills, School-age children, Conversation observation measures
언어치료의 궁극적인 목적이 다른 사람과의 의사소통을 원활하 게 하기 위함임을 고려할 때 최근 언어치료 분야에서 화용언어 능 력의 중요성이 강조되는 것은 자연스러운 일이라고 할 수 있다. 이에 따라 언어평가에서도 어휘나 문법정확성 외에도 화용언어 능력에 대한 평가의 중요성이 커지고 있다. 국외에서는 이미 다양한 화용언 어 능력 평가 절차가 개발되어 있었지만 국내에는 화용언어 능력을 검사하는 도구가 매우 한정되어 있으며, 그나마 화용언어를 전문적, 공식적으로 평가하는 도구는 전무한 실정이었다. 학령전기에 전반 적인 언어공식평가에서 의사소통기능 중심의 화용언어 능력을 부 분적으로 평가하고는 있으나 화용언어 전반을 다루고 있지는 못하 고 있다가(Lee, 2010) 최근 들어 국내에서도 화용언어 능력에 대한 평가 절차들이 개발되기 시작했다(Song, Kim, Lee, \& Kim, 2017).
화용언어 능력은 학령전기뿐 아니라 아동이 유치원이나 학교 등 의 교육기관에 진학하고, 부모님이나 가족뿐 아니라 또래나 선생님 들과의 관계를 맺기 시작하면서 점차 학업수행 및 학교생활의 성 공에 더 큰 영향을 주는 등, 중요성이 커진다(Nippold et al., 2014). 학령전기에는 언어발달에 있어 구문길이가 급격히 늘어나면서 평 균발화길이(MLU)나 어휘량 등이 발달의 주요 지표가 되는 반면 에, 학령기에는 구문이나 형태론적 성장보다도 다른 사람을 배려하 거나 상황에 맞게 말투나 내용을 조절하는 대화기술이나 담화능 력 발달이 두드러진다(Nippold, 2007). 특히, DSM-5에서 사회적 의사소통장애(social communication disorder)가 장애명으로 등 장한 후(American Psychiatric Association, 2013), 주 문제가 화용 문제인 언어장애(pragmatic language impairment; Bishop \& Nor- 
bury, 2002)에 대한 진단과 타 장애와의 변별에 대한 시도가 더욱더 활발히 진행되고 있다(Jin \& Pae, 2014; Song, Yang, Kim, \& Yim, 2016).

최근 학령기 언어발달에 대한 관심이 높아지면서 학령기 언어능 력을 평가할 수 있는 검사도구가 점차 늘어나고 있으며 어휘나 읽기 능력검사 및 의미, 구문, 화용 등 전반적인 언어능력을 평가할 수 있 는 공식검사도구들도 많아지고 있다. 특히 화용영역에서는 학령기 아동 언어검사(LSSC; Lee, Heo, \& Jang, 2015)에서 담화이해 과제 가 포함되어 담화에서의 화용언어 능력을 평가할 수 있게 되었으 며, 직접적으로 시청각자료를 활용하여 아동에게 직접 화용과제를 실시하여 평가하는 화용검사도구가 개발 중에 있기도 하다(Song et al., 2017).

화용언어 능력에 대한 평가 방법은 직접적 대화 행동 관찰, 양육 자 작성 체크리스트, 구조화된 상황에서의 공식적인 검사 등, 크게 세 가지로 나누어 연구가 진행되어 왔다. 전통적으로 화용언어 능 력을 주로 의사소통 기능, 즉 화행 분석으로 생각하였기 때문에 직 접 자연스러운 상황에서의 대화나 특정 상황에서의 의사소통 행 동을 수집하고 분석하는 행동관찰이 화용 평가의 대부분을 차지 하였다(Oh, Lee, \& Kim, 2012). 그러나 이 방법은 그 검사자체의 타 당성을 인정받음에도 불구하고 다른 검사와의 상관을 통한 공인타 당도나 평가자 간/평가자 내 신뢰도 문제가 제기되어 왔다.

양육자 작성 체크리스트의 경우에는 일상생활에서의 의사소통 행동을 모두 고려하지 못한다는 단점이 있으나 대상자와 일상을 함께하는 사람이면 비교적 짧은 시간에 아동의 언어능력의 평가가 가능하고 행동관찰에서 기회가 없어 관찰하지 못하는 항목에 대 해서도 평가가 가능하다는 장점이 있다. 특히 화용능력에 대한 질 문지를 통한 선별은 학령기 아동 중 심화평가 및 언어중재 대상자 를 선별해내는 데 가장 효과적인 것으로 보고되기도 하였다(Damico \& Oller, 1980). 해외에서 화용능력을 평가하는 체크리스트로 가장 널리 사용되고 있는 아동 의사소통 체크리스트(Children's Communication Checklist, CCC; Bishop, 1998, 2003)는 다른 영역 의 언어능력에 대한 평가도 일부 포함하고 있으나 전반적으로 화용 능력에 중심을 둔 평가도구로, 화용언어 능력에 어려움을 보이는 장애 아동, 특히 자페범주성장애 아동을 확인하는 데 자주 사용되 고 있다. 임상현장에 CCC가 널리 사용되면서 이후 타당도와 신뢰 도 검증연구를 거쳐(Norbury, Nash, Baird, \& Bishop, 2004) 일반 아동과 장애 아동 간 변별뿐 아니라 자폐범주성장애 하위장애 간 변별(Farmer \& Oliver, 2005; Verté et al., 2006)이나 자폐범주성장 애와 주의력결핍과잉행동장애나 단순언어장애 등 다른 장애 간 구 분(Geurts et al., 2004; Geurts \& Embrechts, 2008; Seo \& Ahn, 2015)
이나 자폐범주성장애와 그와 유사한 사회적 의사소통장애(Jin \& $\mathrm{Pae}, 2014$ ) 변별 연구에 활발히 활용되고 있다. 국내에서 진행된 메 타연구에 따르면 이러한 변별 연구들 중에서 자폐범주성장애 아동 과 주의력집중과잉행동장애 아동을 아동의사소통체크리스트 (CCC)로 구별해내는 것은 효과적인 것으로 나타났다(Song et al., 2016).

국내에서도 임상현장에서나 연구에서 아동의사소통체크리스 트(CCC)를 번역해서 사용하거나(Jin \& Pae, 2014) 학교에서 아동 들의 의사소통을 살펴보기 위해 교사들이 작성하는 학령기 아동 용 의사소통 능력 평가지(Yoon \& Lee, 2007)를 개발하여 사용하 는 등 화용능력을 체크리스트로 평가하기 위한 노력들이 있었으나 이를 표준화하여 사용하지는 못하는 상황이다. 아동화용언어체크 리스트(CPLC)는 CCC나 화용 관련 선행연구에서 화용능력의 주 요 요인으로 언급되어온 차례 주고받기, 의사소통 기능, 주제관리, 비언어적 의사소통 등의 영역으로 구성된 부모 작성 체크리스트로 예비연구를 통해 문항의 양호도와 내적타당도가 검증되었으며 (Kim, 2014; Oh et al., 2012), 현재 표준화작업 중에 있다. 화용능력 을 다루는 체크리스트는 비교적 간단한 문항으로 구성된 절차이 므로 공인타당도나 내적타당도나 신뢰도가 검증되는 데서 그치지 않고 실제 대화나 상호작용에서의 의사소통 능력을 잘 반영할 수 있는지 살펴봄으로써 실질적, 임상적 타당성을 검증할 필요가 있다.

본 연구는 학령기 일반 및 화용문제를 가진 언어장애 아동을 대 상으로 아동화용언어체크리스트(CPLC)의 타당도 검증을 위하여 실제 대화에서의 대화기술, 의사소통 능력 측정치와 CPLC 결과 간 상관을 살펴봄으로써 CPLC가 실제 대화에서의 화용능력을 잘 반 영할 수 있는지 살펴보고자 한다. 이를 위해 학령기 일반 및 화용문 제를 가진 언어장애 아동을 대상으로 대화관찰에서의 두 집단 간 차이가 CPLC에서도 나타나는가를 살펴보고, CPLC 각 하위점수 와 대화관찰에서 그에 해당하는 측정치 간 상관이 있는지를 살펴 봄으로써 CLPC가 실제 대화에서의 화용능력을 반영할 수 있는지 타당성을 살펴보고자 한다.

\section{연구방법}

\section{연구대상}

본 연구에는 서울·경기, 경상도 지역의 초등학교 1-4학년에 재학 중인 언어장애아동 14 명과 학년과 생활연령을 일치시킨 일반 아동 14 명 등, 총 28 명이 참여하였다. 대상아동의 선정과 특성 파악을 위하 여 한국판 웩슬러 아동지능검사(K-WISC-IV; Kwak, Oh, \& Kim, 2011)의 지각추론영역검사와 학령기아동언어검사(LSSC; Lee et al., 
Table 1. Characteristics of participants

\begin{tabular}{lccr}
\hline Group & Age (mo) & $\begin{array}{c}\text { K-WISC-IV percep- } \\
\text { tion \& inference }\end{array}$ & $\begin{array}{c}\text { LSSC language } \\
\text { quotient }\end{array}$ \\
\hline Typically developing & $106.29(12.89)$ & $116.71(11.90)$ & $126.50(10.32)$ \\
Language disorder & $111.00(12.86)$ & $83.00(9.90)$ & $91.64(23.39)$ \\
Total & $8.93(1.60)$ & $104.97(18.54)$ & $108.90(23.11)$ \\
\hline
\end{tabular}

Values are presented as mean (SD).

K-WISC-IV = Korean-Wechsler Intelligence Scale for Children (Kwak, Oh, \& Kim, 2011); LSSC=Language Scale for School-aged Children (Lee, Heo, \& Jang, 2015).

2015)를 실시하였다. 두 집단 모두 K-WISC-IV검사에서 80 이상이 고 부모나 선생님에 의해 감각, 행동 문제가 없다고 보고된 아동이 었으며 언어장애 아동 집단의 경우 부모님이나 담당 치료사로부터 화용문제를 가진다고 보고된 아동으로 선정하였다. 본 연구에 참 여한 아동의 집단별 학년별 인원과 지능검사 및 학령기 아동 언어 검사 특성은 Table 1 과 같다.

두 집단 간 특성을 통계적으로 비교하여 $t$-검정을 실시한 결과 대 상아동의 월령은 두 집단 간 유의한차이가 없었으며 K-WISC-IV의 지각추론 점수 $\left(t_{(2,26)}=8.149, p<.001\right)$ 와 LSSC의 총 언어지수 $\left(t_{(2,26)}=\right.$ $5.102, p<.001)$ 는 유의한 차이가 있었다.

\section{연구 절차 및 분석}

\section{자료수집 도구 및 절차}

자료수집은 아동별로 아동의 집이나 언어치료실의 독립된 방에 서 실시되었다. 먼저 아동의 어머니에게 화용언어체크리스트(CPLC; Oh et al., 2012) 설문지 작성을 안내하였으며, 아동과는 선별검사인 지능검사를 실시하고 대화 샘플 수집과 학령기아동언어검사 (LSSC)를 실시하였다.

아동화용언어체크리스트(CPLC)는 학령전기 5 세 아동부터 13 세 아동들의 화용 결함 여부를 확인할 수 있는 양육자 작성 체크리 스트로 총 검사 소요시간은 10-20분으로 44개 문항에 4점 척도로 응답하도록 구성되어 있다(Kim, 2014; Oh et al., 2012). 대상 아동 의 화용 프로파일을 또래 아동과 상대적으로 비교함과 동시에 화 용언어의 4 개 하위영역별(담화관리, 상황.청자에 따른 조절 및 적 용, 의사소통 의도, 비언어적 의사소통) 질적 특징을 파악하여 치 료교육의 목표 선정에 도움을 주는 것을 목적으로 하였다. 아직 표 준화가 완료되지 않았으나 예비연구를 통해 내적타당도와 문항일 치도가 확인되었다(Oh et al., 2012).

대화샘플 수집 절차는 전반적으로 Heo와 Lee (2012) 및 Nippold 등(2014)의 절차를 따랐으며, 분석 및 측정치를 본 연구의 목적에 맞게 조정하였다. 학령기 아동에 적절하다고 보고된 '학교생활, 취 미 및 여가 활동, 가족소개' 등의 세 가지 주제에 대하여 A5 크기의
사진을 주제별로 각각 5 장씩 준비하였다. 주제별로 3 개의 봉투에 담아 아동에게 봉투를 제시하고 어떤 순서와 방법으로 봉투를 열 어 대화를 나눌지 정하도록 하였다. 아동이 먼저 주제에 맞는 대화 를 시작하도록 기다려주었으며 대화를 시작하지 않는 경우 “**이 의 학교 생활 어떤지 이야기 해줄 수 있어?”, "**이 가족 좀 소개해 줄 수 있어?”, “**이 취미는 무엇인지 이야기해줄래?”하고 질문하여 촉진하였다. 대화 중에는 아동의 말에 긍정적인 피드백을 해주면서 “응”, “그랬구나”, "또” 등의 중립적인 반응을 유지하도록 하였다.

자료수집은 주연구자와 1 급 언어재활사 자격증을 가진 언어치료 경력 10 년 이상의 보조검사자가 분담하여 실시하였다. 보조검사자 와 주연구자는 일반 아동과 장애 아동 검사과정을 서로 지켜보며 95\% 일치도를 나타낼 때까지 피드백 과정을 거쳤으며, 분석의 일관 성을 위하여 예비검사한 아동 2 명의 자료를 분석하고 토의하여 분 석과정을 거쳐 분석의 일관성을 유지하였다.

\section{자료 전사}

대화자료의 전사는 수집 후 1 주일 이내에 녹화된 영상을 보면서 본격적으로 주제가 제시되기 전의 관계형성을 위한 대화나 주제 이 외의 대화, 불명료한 대화를 제외하고 10-15분가량의 대화를 전사 하였다. 전사된 발화자료의 대화 차례 구분은 Lee와 Kim (2001)과 Heo와 Lee (2012)를 따랐으며 차례 구분 후 발화는 의사소통 단위 (C-unit)로 구분하였다.

\section{자료의 분석 및 측정}

아동화용언어체크리스트(CPLC)의 분석은 총점과 각 하위영역 별 점수를 산출하여 분석하였다. 총 44 개의 4 점 척도 문항(항상 그렇 다 $=3$, 그렇다 $=2$, 그렇지 않다 $=1$, 전혀 그렇지 않다 $=0$ )으로 각 문 항을 0-3점까지 배점하여 담화관리 영역 9문항 0-27점, 상황에 따른 조절 영역 15 문항 $0-45$ 점, 의사소통 의도 영역 12 문항 $0-36$ 점, 비언어 적 의사소통 영역 8문항 0-24점으로 총점 0-132점으로 채점하였다.

아동화용언어체크리스트(CPLC) 결과와 대화분석 간 비교를 위 하여 CPLC의 하위영역별로 대화관찰 샘플에서 대응되는 비교 측 정치를 설정하였다. 그러나 예비연구 결과 CPLC의 비언어적 의사 소통 영역은 과제특성상 대화관찰에서 나타나는 특성의 절대적인 수가 부족하였고 결과적으로 CPLC와 대화관찰 간의 직접적인 비 교가 어려웠다. 그러므로 본 연구에서는 이를 제외한 담화관리, 상 황에 따른 조절, 의사소통 의도 등 CPLC의 나머지 세 영역을 각각 대화관찰에서 대응되는 발화분석 측정치를 설정하여 비교분석을 실시하였다.CPLC의 첫 번째 하위영역인 담화관리(주제관리와 대화 차례 주고받기)에 해당하는 대화관찰 측정치는 Heo와 Lee (2012) 
의 주제 관리와 대화차례 주고받기의 종속측정치의 정의와 측정 방법을 사용하였다. 대화차례 주고받기는 대화차례당 C-unit 수, 총 C-unit 수와 대화차례에서 개시와 유지, 중첩과 중단이 차지하 는 비율을 측정하였다. 두 번째 하위영역인 상황에 따른 조절은 대 화 관찰에서 언어사용역(register)의 적절한 변화 빈도수와 적절한 전제 표현 빈도수로 관찰하였다(Paul, 2007). 대화 과제에서 언어사 용역(register)은 혼잣말이나 연구자에게 하는 말, 양육자에게 하는 말 등으로 언어맥락이 바뀌는 경우 형식적으로 이를 높임말/반말/ 문어체 등으로 언어형식이 적절하게 바뀌는 경우의 수로 정의하였 다. 전제(presupposition)는 청자와의 경험공유 정도에 따라 추가적 인 설명이나 생략, 대명사로 표현한 경우, 대화 과제의 일부를 반복 하여 연구자 이외 보호자와 함께 하도록 기회를 준 후 이전에 했던 것과는 의식적으로 다르게 표현하거나 생략이나 대용표현 등이 나 타나는 경우의 수로 조작적으로 정의하였다. 세 번째 CPLC의 의사 소통 의도 영역은 대화 샘플에서 나타난 각 의사소통 기능의 비율 측정치와 비교하였다(Fey, 1986; Jin \& Pae, 2014). 의사소통 기능은 기본적으로 주장하기(assertive) (요구하기/주장하기/수행하기)와 반응하기(responsiveness) (요구하기에 대한 반응/수행하기에 대한 반응)의 두 가지로 크게 나누는 Fey (1986)의 의사소통 체계로 분 류하여 빈도수를 산출하였다. 이상 화용언어체크리스트와 그에 상 응하는 대화 관찰에서의 구체적 종속 측정치 정의 및 측정방법은

Table 2와 같다.

\section{통계 분석}

집단별로 화용언어체크리스트의 총점과 하위영역별 점수, 대화
관찰 분석 항목별 결과치에 대한 기술통계 분석을 실시하였고, PASW Statistics (SPSS version 18.0) 프로그램을 이용하여 집단 간 차이에 대하여 두 독립표본 $t$-검정을 실시하였다. 그런 다음 화용언 어체크리스트의 영역별 점수와 대화관찰 분석치 간 상관을 분석하 기 위하여 Pearson 상관분석을 실시하였다.

\section{신뢰도}

분석의 신뢰도를 측정하기 위하여 선행연구에서 신뢰도가 검증 된 $\mathrm{CPLC}$ 를 제외한 대화 샘플 분석에 대하여 검사자 간 신뢰도를 검증하였다. 총 아동수의 $20 \%$ 인 5 명에 해당하는 아동의 대화샘플 의 담화관리, 상황에 따른 변이, 의사소통 의도 분석에 대하여 3 년 경력의 1 급 언어치료사 1 명을 제 2 분석자로 선정하였다. 일차적으 로 독립적으로 영역별 분석을 마친 후 의견 일치가 이루어지지 않 은 항목에 대하여 재논의 과정을 걸쳐 최종적으로 일치하는 항목 의 수를 일치 항목과 불일치 항목수의 합으로 나누어 100을 곱하 여 신뢰도를 산출하였다. 그 결과 담화관리 $96.00 \%$, 의사소통 의도 $97.67 \%$, 상황에 따른 조절 $96.46 \%$ 로 대체로 높은 수준의 일치도를 보였다.

\section{연구결과}

\section{화용언어체크리스트 분석결과}

대상 아동 집단별, 하위영역별 아동화용언어체크리스트(CPLC) 의 기술통계와 $t$-검정 결과는 Table 3 에 제시하였다.

일반 아동의 영역별 평균과 표준편차를 살펴보면 가장 점수가

Table 2. CPLC subareas and corresponding areas in conversation sample analysis

\begin{tabular}{|c|c|c|}
\hline \multicolumn{2}{|c|}{ CPLC sub-areas \& Items } & \multirow{2}{*}{$\begin{array}{l}\text { Conversation observation measures } \\
\text { Topic management (Heo \& Lee, 2012) } \\
\text { - Percentage of topic initiation (total/appropriate/inappropriate) } \\
\text { - Percentage of topic maintenance (total/appropriate/inappropriate) }\end{array}$} \\
\hline $\begin{array}{l}\text { Discourse } \\
\text { management }\end{array}$ & $\begin{array}{l}\text { Topic management } \\
\text { - Topic initiation/maintenance/change }\end{array}$ & \\
\hline & Turn-taking in conversation & $\begin{array}{l}\text { Conversational turn management (Heo \& Lee, 2012) } \\
\text { - \% of turn initiation/maintenance/overlap/stop page } \\
\text { - C-unit per turn }\end{array}$ \\
\hline $\begin{array}{r}\text { Contextual } \\
\text { variation }\end{array}$ & $\begin{array}{l}\text { Adjustment for situation and listener } \\
\text { - Reference skills } \\
\text { - Register }\end{array}$ & $\begin{array}{l}\text { Number of presupposition expression (Paul, 2007) } \\
\text { - Shared experience or knowledge } \\
\text { - Task repetition } \\
\text { Number of register change (Paul, 2007) } \\
\text { - Respectful words }\end{array}$ \\
\hline $\begin{array}{l}\text { Communication } \\
\text { intent }\end{array}$ & $\begin{array}{l}\text { Adequacy and variability of communi- } \\
\text { cational function, intent } \\
\text { Cognitive communication function } \\
\text { Indirect intent expression }\end{array}$ & $\begin{array}{l}\text { Variability of communicational function (Fey, 1986; Jin \& Pae, 2014) } \\
\text { - Frequency of assertive function; request for information/request for action/request for clarification/request for } \\
\text { attention/comment/statement/disagreement/performatives } \\
\text { - Frequency of responsive function; responsive to requests for information/responsive to request for action/re- } \\
\text { sponsive to request for clarification/responsive to request for attention/responsive to assertive \& performative } \\
\text { - Frequency of other functions; repetition/others }\end{array}$ \\
\hline
\end{tabular}

$\mathrm{CPLC}=$ Children's Pragmatic Language Checklist. 
높은 영역은 의사소통 의도(기능) 영역으로 35.14 (4.70)이었으며, 상황에 따른 조절 능력, 담화관리, 비언어적 의사소통 순으로 나타 났다. 장애 아동의 가장 평균이 높은 영역 또한 의사소통 의도 영역 으로 22.29 (3.79)이었으며, 상황에 따른 조절 능력과 담화관리 순

Table 3. Results on CPLC

\begin{tabular}{lccccc}
\hline Sub-areas & $\begin{array}{c}\text { Typically devel- } \\
\text { oping }(\mathrm{N}=14)\end{array}$ & $\begin{array}{c}\text { Language dis- } \\
\text { order }(\mathrm{N}=14)\end{array}$ & $t$ & df & $p$-value \\
\hline Discourse management & $24.43(3.37)$ & $15.21(3.51)$ & 7.086 & 26 & .000 \\
Contextual variation & $32.79(4.56)$ & $20.43(4.64)$ & 7.110 & 26 & .000 \\
Communication intent & $35.14(4.70)$ & $22.29(3.79)$ & 8.030 & 26 & .000 \\
Total & $110.14(14.52)$ & $66.50(22.17)$ & 6.161 & 26 & .000 \\
\hline
\end{tabular}

Values are presented as mean (SD).

$\mathrm{CPLC}=$ Children's Pragmatic Language Checklist.
으로 점수가 높았다. 전체적으로 총점 및 4 개 하위영역 모두에서 일 반 아동에 비해 장애 아동 집단이 낮은 수행을 보였으며, 이를 통계 적으로 검증한 결과 총점과 담화관리 $\left(t_{(2,26)}=7.086, p<.001\right)$, 상황 에 따른 조절 $\left(t_{(2,26)}=7.110, p<.001\right)$, 의사소통 의도 $\left(t_{(2,26)}=8.030\right.$, $p<.001)$ 의 모든 영역별 점수에서 집단 간 차이는 유의하였다.

\section{대화관찰 분석 결과}

일반 아동과 화용문제를 보이는 언어장애 아동의 검사자와의 대화 샘플에서 나타난 대화차례 주고받기와 주제 운용능력 등의 측정치를 살펴본 결과 각 종속 측정치들의 기술통계와 집단 간 비 교를 위한 $t$-검정 결과는 Table 4 와 같다.

일반 아동 집단과 화용문제를 보이는 언어장애 아동은 대화차례

Table 4. Results of group differences in conversation observation measures

\begin{tabular}{|c|c|c|c|c|c|c|}
\hline \multicolumn{3}{|l|}{ Dependent variables } & Typically developing & Language disorder & $t$ & $p$-value \\
\hline \multicolumn{3}{|l|}{ Total number of C-unit } & $85.79(35.12)$ & $95.07(30.77)$ & -.744 & .463 \\
\hline \multicolumn{3}{|l|}{ C-unit per turn } & $1.06(.38)$ & $1.28(.58)$ & 1.194 & .243 \\
\hline \multirow[t]{10}{*}{ Discourse management } & Topic management & Turn initiation (\%) & $11.89(4.59)$ & $8.76(3.25)$ & 1.601 & .122 \\
\hline & & Turn maintain (\%) & $77.91(10.82)$ & $73.25(12.24)$ & 1.067 & .296 \\
\hline & & Turn overlap (\%) & $3.69(3.23)$ & $6.39(3.42)$ & -2.151 & .041 \\
\hline & & Turn stoppage (\%) & $6.59(7.82)$ & $11.61(10.31)$ & -1.453 & .158 \\
\hline & Conversational turn management & Total topic initiation (\%) & $10.38(5.91)$ & $10.79(6.69)$ & -.172 & .865 \\
\hline & & Appropriate & $84.26(21.98)$ & $58.49(32.91)$ & 2.436 & .022 \\
\hline & & Inappropriate & $15.74(21.98)$ & 44.37 (30.69) & -2.837 & .009 \\
\hline & & Total topic maintenance (\%) & $77.33(16.21)$ & $72.24(13.65)$ & .899 & .377 \\
\hline & & Appropriate & $96.88(3.38)$ & $84.28(8.76)$ & 5.021 & .000 \\
\hline & & Inappropriate & $2.93(3.48)$ & $15.69(8.84)$ & -5.029 & .000 \\
\hline \multirow[t]{3}{*}{ Contextual variation } & Register change & & $.80(.94)$ & $1.00(.50)$ & -.586 & .564 \\
\hline & Presupposition (shared knowledge) & & $1.60(1.76)$ & $.11(.33)$ & 2.483 & .021 \\
\hline & Presupposition (task repetition) & & $.86(.83)$ & $0(0)$ & 3.090 & .005 \\
\hline \multirow[t]{14}{*}{ Communication intent } & Assertive & RQIN & $2.38(2.80)$ & $3.67(7.68)$ & -.612 & .546 \\
\hline & & ROAC & $.50(.89)$ & $1.33(2.06)$ & -1.414 & .171 \\
\hline & & ROCL & $1.88(2.58)$ & $1.78(1.56)$ & .102 & .919 \\
\hline & & RQAT & $.38(1.02)$ & $1.44(1.88)$ & -1.856 & .076 \\
\hline & & ASCO & $25.19(17.91)$ & $24.78(20.57)$ & .052 & .959 \\
\hline & & ASST & $12.44(8.51)$ & $6.11(6.29)$ & 1.944 & .064 \\
\hline & & ASDA & $2.31(2.41)$ & $3.56(1.94)$ & -1.319 & .200 \\
\hline & & ASPE & $1.38(2.16)$ & $.55(1.01)$ & 1.068 & .297 \\
\hline & Responsive & RSIN & $14.75(11.83)$ & $30.11(20.46)$ & -2.395 & .025 \\
\hline & & RSAC & $.31(.60)$ & $1.67(2.60)$ & -2.022 & .055 \\
\hline & & RSCL & $6.94(5.43)$ & $12.33(10.40)$ & -1.717 & .099 \\
\hline & & RSAT & $.06(.25)$ & $.44(.72)$ & -1.935 & .065 \\
\hline & & RSAS & $5.00(4.24)$ & $11.33(6.71)$ & -2.904 & .008 \\
\hline & Others & & $.31(.60)$ & $1.56(1.42)$ & -3.074 & .005 \\
\hline
\end{tabular}

Values are presented as mean (SD).

ROIN = request information; $R O A C=$ request action; $R O C L$ = request clarification; $R O A T=$ request attention; $A S C O=$ comment; $A S S T=$ statement; $A S D A=$ disagreement; $A S P E=$ performatives; RSIN = response to ROIN; RSAC= response to ROAC; $\mathrm{RSCL}=$ response to ROCL; RSAT = response to ROAT; RSAS= response to assertive \& performatives (ASCO, ASST, ASDA, ASPE); others= repetition and etc. 
Table 5. Correlation between topic and turn maintenance measures and CPLC scores

\begin{tabular}{|c|c|c|c|c|c|c|c|c|c|c|c|c|}
\hline \multirow{2}{*}{ Sub-areas } & \multirow{2}{*}{$\begin{array}{l}\text { Total num- } \\
\text { ber of C-unit }\end{array}$} & \multirow{2}{*}{$\begin{array}{l}\text { C-unit } \\
\text { per turn }\end{array}$} & \multicolumn{4}{|c|}{$\%$ of Turn } & \multicolumn{3}{|c|}{$\%$ of Topic initiation } & \multicolumn{3}{|c|}{$\%$ of Topic maintenance } \\
\hline & & & Initiation & Maintenance & Overlap & Stop-page & Total & Relevant & Irrelevant & Total & Relevant & Irrelevant \\
\hline Discourse management & -.066 & .230 & .231 & .134 & -.160 & -.253 & -.184 & $.482^{* *}$ & $-.471^{*}$ & .158 & $.644^{* *}$ & $-.636^{* *}$ \\
\hline Contextual variation & -.187 & .254 & .238 & .169 & -.272 & -.250 & -.152 & $.507^{* *}$ & $-.538^{* *}$ & .163 & $.660^{* *}$ & $-.649^{* *}$ \\
\hline Communication intent & -.060 & .323 & .202 & .217 & -.196 & -.328 & -.144 & $.516^{* *}$ & $-.548^{* *}$ & .210 & $.678^{* *}$ & $-.671^{* *}$ \\
\hline Total & -.047 & .294 & .282 & .110 & -.089 & -.275 & -.043 & $.397^{*}$ & $-.410^{*}$ & .120 & $.588^{* *}$ & $-.581^{* *}$ \\
\hline
\end{tabular}

$\mathrm{CPLC}=$ Children's Pragmatic Language Checklist.

${ }^{*} p<.05,{ }^{* *} p<.01$.

Table 6. Correlation between communication intent measures and CPLC scores

\begin{tabular}{lcccccccccccccc}
\hline Sub-areas & RQIN & RQAC & ROCL & ROAT & ASCO & ASST & ASDA & ASPE & RSIN & RSAC & RSCL & RSAT & RSAS & other \\
\hline Discourse manage & -.110 & -.024 & -.196 & -.293 & .040 & .162 & -.043 & .137 & -.226 & -.317 & -.279 & -.135 & $-.562^{* *}$ & $-.649^{* *}$ \\
Contextual variation & -.163 & -.001 & -.257 & -.315 & .046 & .280 & -.041 & .015 & -.244 & -.344 & -.277 & -.088 & $-.598^{* *}$ & $-.667^{* *}$ \\
Communication intent & -.120 & -.087 & -.218 & -.238 & -.056 & .113 & -.004 & .153 & -.279 & -.383 & -.283 & -.192 & $-.544^{* *}$ & $-.578^{* *}$ \\
Nonverbal & -.231 & .045 & -.375 & -.146 & .102 & .377 & -.152 & -.016 & $-.408^{*}$ & -.166 & $-.412^{*}$ & -.137 & $-.584^{* *}$ & $-.467^{*}$ \\
Total & -.150 & -.043 & -.257 & -.273 & .004 & .204 & -.040 & .105 & -.294 & -.359 & -.316 & -.161 & $-.603^{* *}$ & $-.639^{* *}$ \\
\hline
\end{tabular}

$\mathrm{CPLC}=$ Children's Pragmatic Language Checklist; $\mathrm{ROIN}=$ request information; $\mathrm{ROAC}=$ request action; $\mathrm{ROCL}=$ request clarification; $\mathrm{ROAT}=$ request attention; $\mathrm{ASCO}=\mathrm{comment}$; ASST = statement; $A S D A=$ disagreement; $A S P E=$ performatives; $R S I N=$ response to $R O I N ; R S A C=$ response to $R Q A C ; R S C L=$ response to RQCL; RSAT=response to RQAT; RSAS = response to assertive \& performatives (ASCO, ASST, ASDA, ASPE); others= repetition and etc.

${ }^{*} p<.05,{ }^{* *} p<.01$.

Table 7. Correlation between contextual variation measures and CPLC scores

\begin{tabular}{lccc}
\hline Sub-areas & $\begin{array}{c}\text { Register varia- } \\
\text { tion }\end{array}$ & $\begin{array}{c}\text { Presupposition for } \\
\text { shared knowledge }\end{array}$ & $\begin{array}{c}\text { Presupposition } \\
\text { for task repetition }\end{array}$ \\
\hline Discourse management & .226 & .300 & $.494^{*}$ \\
Contextual variation & .224 & .276 & $.422^{*}$ \\
Communication intent & .399 & .234 & $.459^{*}$ \\
Total & .299 & .269 & $.476^{*}$ \\
\hline
\end{tabular}

$\mathrm{CPLC}=$ Children's Pragmatic Language Checklist.

${ }^{*} p<.05$.

중첩 빈도 $\left(t_{(2,26)}=-2.151, p<.05\right)$, 적절한 주제개시율 $\left(t_{(2,26)}=2.436\right.$, $p<.05)$, 부적절한 대화개시율 $\left(t_{(2,26)}=-2.837, p<.01\right)$, 적절한 주제 유지율 $\left(t_{(2,26)}=5.021, p<.001\right)$, 부적절한 주제유지율 $\left(t_{(2,26)}=-5.029\right.$, $p<.001)$ 에서 유의한 차이를 보였고 상대와의 공유지식에 대한 전제 표현 $\left(t_{(2,26)}=2.483, p<.05\right)$ 이나 과제 반복에 따른 전제 $\left(t_{(2,26)}=3.090\right.$, $p<.01)$ 에서도 차이를 보였다. 의사소통 기능에서는 정보요구에 대 한 반응 $\left(t_{(2,26)}=-2.395, p<.05\right)$, 주장. 수행에 대한 반응 $\left(t_{(2,26)}=-2.904\right.$, $p<.01)$, 기타 의사소통 기능 $\left(t_{(2,26)}=-3.704, p<.01\right)$ 에서 유의한 차 이를 나타냈다.

\section{화용언어체크리스트와 대화관찰 분석 간 상관분석 결과}

화용언어체크리스트 결과와 대화관찰 측정치 중 대화차례와 주 제관리 능력에 관한 측정치의 상관분석 결과는 Table 5 에 제시하였 다. CPLC의 담화관리 점수는 대화 측정치들 중 주로 주제관리 측
정치들과 유의한 상관을 보였으며 대화차례 관리 측정치들과는 유 의한 상관이 없었다. CPLC의 상황에 따른 조절 하위영역 점수는 적절/부적절한 주제개시율과 적절/부적절한 주제유지율과 .507.660 정도의 유의한 상관을 보였으며 CPLC 총점은 적절/부적절한 주제개시율과 .390-.410 정도의 상관이, 적절/부적절한 주제유지율 과는 $.581-.588$ 의 유의한 상관이 있었다.

$\mathrm{CPLC}$ 의 의사소통 의도 하위영역 점수 및 CPLC 총점은 대화 측 정치들 중 주장하기 및 수행하기에 대한 반응 및 기타 의사소통 기 능과 유의한 상관을 보였다 $(p<.01)$ (Table 6). 주장하기와 수행하기 에 대한 반응은 의사소통 의도뿐 아니라 CPLC의 총점이나 다른 영역 점수와도 유의한 상관을 보였다 $(p<.01)$.

$\mathrm{CPLC}$ 의 상황에 따른 조절 하위영역 점수는 대화 측정치들 중 과제 반복에 따른 전제 표현과 유의미한 상관을 보였으며 $(p<.05)$, $\mathrm{CPLC}$ 의 비언어적 의사소통 하위영역 점수는 대화관찰에서의 비 언어적 의사소통 점수와 유의미한 상관을 보였다. CPLC 총점은 과 제 반복에 따른 전제 표현과 대화관찰에서의 비언어적 의사소통 점수와 유의한 상관을 보였다(Table 7).

\section{논의 및 결론}

본 연구는 학령기 일반 아동과 화용문제가 보고된 언어장애 아 동을 대상으로 하여 직접 관찰한 대화에서의 대화기술 및 의사소 
통 능력의 집단 간 차이가 아동화용언어체크리스트에서도 나타나 는지, 아동화용언어체크리스트와 대화관찰 측정치들 사이에 상관 관계를 살펴봄으로써 아동화용언어체크리스트(CPLC)의 타당성 을 검증하는 것을 목적으로 하였다.

먼저 집단 간의 차이가 CPLC와 대화관찰 측정치들에서 나타나 는지 살펴본 결과, 대화관찰 측정치에서 두 집단 간 차이가 비일관 적이었던 데 비해 CPLC에서는 총점과 모든 하위영역 점수에서 유 의미한 집단 간 차이가 관찰되어, 일반 아동이 언어장애 아동보다 CPLC에서 전반적으로 높은 수행을 보였음을 알 수 있었다. 이는 CPLC 문항개발을 위한 예비연구에서도 장애별로 다른 CPLC 프 로파일을 보이긴 했으나 전반적으로 장애 아동과 일반 아동 간에 는 뚜렷한 유의미한 차이를 보인 것과 일치하는 결과라 할 수 있다 (Oh et al., 2012).

대화관찰 측정치들 중에서는 대화차례 관리에서 대화차례 중첩 률과 적절/부적절한 주제개시율과 적절/부적절한 주제유지율에서 집단 간 차이가 유의하였으며, 대화차례 개시율과 유지율에서는 유 의한차이가 없었다. 자폐범주성장애 아동과 언어학습장애 아동을 대상으로 한 기존의 연구에서는 오히려 대화중첩률보다는 대화차 례 개시율에서 집단 차이가 보고되었으며(Choi \& Lee, 2013; Heo \& Lee, 2012), ADHD 아동에서는 대화 중첩 및 방해 비율이 일반 아동보다 높았다고 보고되는(Kim \& Lee, 2007) 등 연구대상의 장 애 종류나 과제에 따라 다른 프로파일을 보이고 있다. 본 연구에서 는 주제 개시와 유지로 나누어 적절성만을 기준으로 분류하였는데 추후 앞뒤 문맥과의 내용적 연관성(contingency) 기준을 추가하여 내용적으로 보다 세밀하게 분석가능하고 실제로 집단 간 차이가 더 명확하게 드러날 가능성이 있을 것이다. 국내외 연구에서도 자 폐범주성장애 아동이 이러한 연관성 있는 발화의 비율이 현저히 낮음이 보고되었으므로(Choi \& Lee, 2015), 이후 집단 간 비교 연구 에서 추가하여 분석한다면 CPLC를 비롯한 화용언어를 평가하는 다른 도구들과의 상관성이 높아질 가능성도 있을 것이다.

의사소통 의도에서는 반응하기 빈도수에서 집단 간 차이가 유의 했으나 주장하기에서는 집단 간 차이가 나타나지 않았다. 이는 본 연구에서 장애아동 집단 자료수집 시 평가자가 더 많은 촉진과 질 문을 했을 가능성을 시사하기도 하며, 한편 본 연구에서의 측정치 가 각 의사소통 기능의 빈도에 한정되어 의사소통 기능의 질적인 측면의 차이를 반영하기 어려웠을 가능성도 있다. 실제로 자폐범주 성장애 아동과 사회적 의사소통장애 아동의 개시하기와 반응하기 의사소통을 일반 아동과 비교하여 살펴본 Jin과 Pae (2014)의 경우 개시하기와 반응하기의 빈도뿐 아니라 각 의사소통 기능의 세부유 형을 이탈적, 사회적, 소극적, 독단적, 친사회적으로 나누어 분석한
결과 일반 아동과 장애 아동뿐만 아니라 두 장애아동 간의 차이도 설명할 수 있었다. 본 연구에서는 이렇게 세세한 유형분류가 이루 어지지 않아 집단 간 의사소통 기능 사용 차이를 민감하게 반영하 지 못했을 가능성이 있다. 이밖에 상황에 따른 조절에 해당하는 측 정치로 설정한 전제 및 언어사용역 관찰 결과, 적절하게 사용한 전 제 횟수가 일반 아동이 유의하게 높은 것으로 나타났다.

CPLC의 하위영역별로 그에 대응하는 대화 샘플의 대화분석 측 정치와 상관관계를 살펴본 결과, $\mathrm{CPLC}$ 의 각 하위영역과 그에 상응 하는 일부 대화 측정치 간에 대체로 .40-60 사이로 상관관계가 있 는 것으로 나타났다. 이는 선행연구와도 비슷한 결과인데 Geurts 와 Embrechts (2010)와 Farmer와 Oliver (2005)는 학령전기 아동 을 대상으로 아동의사소통체크리스트(CCC)를 포함한 두 가지 화 용평가 절차 간 상관을 연구한 결과 두 평가도구 모두 부모가 작성 하는 설문지였음에도 낮거나 중간 정도의 상관만이 나타남을 보고 하였다. 또한, CPLC의 담화관리 영역 점수가 대화관찰 측정치의 담화관리 영역과만, 의사소통 기능 점수는 대화관찰 측정치 중 의 사소통 기능 측정치와만 배타적 상관이 있는 것은 아니고, 대화관 찰 측정치 중 주제관리 측정치들은 CPLC의 모든 하위영역과 총점 과 대부분 관련이 있었다. 이는 화용영역이 어휘 등 다른 언어 영역 과도 관련이 있지만(Song et al., 2017) 화용언어 영역 내 하위 측정 치 간 높은 상관을 보이는 것과 관련이 있다. 실제로 CCC-2의 타당 도를 검증하기 위한 Norbury 등(2004)의 연구에서나 CPLC 문항 개발을 위한 예비연구에서도 요인분석 시 각 하위영역이 서로 분명 하게 구분되지 않았다. 이러한 화용영역의 특성 때문에 CPLC 각 하위 점수가 특정 대화 측정치와만 배타적 상관관계를 맺고 있지 는 않으나 전반적으로, 주제 유지와 개시의 적절성 비율과 CPLC 점 수가 가장 높은 상관을 보였다.

자폐범주성장애 아동의 대화능력을 연구한 최근 결과에 따르면 하위집단별로 과도하게 공식적인 말투나 시선관리(gaze management)에 특히 문제를 보이는 등(Paul et al., 2009) 화용영역의 평가 에서 유의한 차이를 보이는 영역은 구조화 및 자연스러운 정도나 과제의 종류에 따라 다양하였다(Klusek, Martin, \& Losh, 2014). 그 러므로 본 연구에서 부모 설문을 통한 화용언어 능력 평가 결과와 실제 아동과 대화를 통해 비슷한 영역을 평가하는 것은 직접/간접 평가의 차이와 하위영역 간에도 측정치에 따라 조건이 매우 달라 높은 상관을 보이기 어려운 점이 있었을 것으로 사료된다.

따라서 화용체크리스트의 검사도구의 평가지표 타당화를 위해 서는 좀 더 자세하고 세분화된 측정치를 사용하여 대화샘플과 비 교하고 그 외에도 다수의 사례 결과를 통한 구인타당도 및 내적 일 치도, 공인타당도 및 전문가 타당도 등의 통계적 방법 외에도 화용 
문제를 가진 아동과 그렇지 않은 아동을 변별해내는 민감도와 특 이도에 의존하는 것이 바람직할 수 있을 것이다.

또한 본 연구의 대상자 또한 1-4학년으로 한정되어 있었으므로 학령기 전반에 걸쳐 지속적으로 발달한다고 보고되는 화용능력의 특성상 고학년 대상자가 포함된 연구를 통해 보완하고 CPLC 표준 화 이후에는 화용영역에 가장 광범위하고 특정한 어려움을 보이는 자폐범주성 장애 및 사회적 의사소통장애 등 다양한 화용문제를 보이는 장애군들의 특성의 자세히 살펴보고, 이 아동들과 일반 아 동들을 정확히 진단할수 있는지 민감도(sensitivity)와특이도(specificity) 연구를 통해 임상적 타당성 연구를 지속적으로 해나갈 필 요성이 있다(O'Neill, 2007).

\section{REFERENCES}

American Psychiatric Association. (2013). Social (pragmatic) communication disorder, 315.39 (F80.89). In Diagnostic and Statistical Manual of Mental Disorders (5th ed., pp. 47-49). Washington, DC: American Psychiatric Publishing.

Bishop, D. V. (1998). Development of the Children's Communication Checklist (CCC): a method for assessing qualitative aspects of communicative impairment in children. The Journal of Child Psychology and Psychiatry and Allied Disciplines, 39, 879-891.

Bishop, D. V. (2003). The Children's Communication Checklist: CCC-2. London: Harcourt Assessment.

Bishop, D. V., \& Norbury, C. F. (2002). Exploring the borderlands of autistic disorder and specific language impairment: a study using standardised diagnostic instruments. Journal of Child Psychology and Psychiatry, 43, 917929.

Choi, J., \& Lee, Y. (2013). Conversational turn-taking and topic manipulation skills of children with high-functioning autism spectrum disorders. Communication Sciences \& Disorders, 18, 12-23.

Choi, J., \& Lee, Y. (2015). Contingency and informativeness of topic maintenance in children with high-functioning autism spectrum disorders. Communication Sciences \& Disorders, 20, 413-423.

Damico, J., \& Oller, J. W. (1980). Pragmatic versus morphological/syntactic criteria for language referrals. Language, Speech, and Hearing Services in Schools, 11, 85-94.

Farmer, M., \& Oliver, A. (2005). Assessment of pragmatic difficulties and socio-emotional adjustment in practice. International Journal of Language \& Communication Disorders, 40, 403-429.
Fey, M. E. (1986). Language intervention with young children. San Diego, CA: College-Hill Press.

Geurts, H. M., \& Embrechts, M. (2008). Language profiles in ASD, SLI, and ADHD. Journal of Autism and Developmental Disorders, 38, 1931-1943.

Geurts, H. M., Verté, S., Oosterlaan, J., Roeyers, H., Hartman, C. A., Mulder, E. J., ... \& Sergeant, J. A. (2004). Can the Children's Communication Checklist differentiate between children with autism, children with ADHD, and normal controls? Journal of Child Psychology and Psychiatry, 45, 1437-1453.

Geurts, H., \& Embrechts, M. (2010). Pragmatics in pre-schoolers with language impairments. International Journal of Language \& Communication Disorders, 45, 436-447.

Heo, H., \& Lee, Y. K. (2012). Conversational turn-taking and topic manipulation skills in conversations of school-age low-achievers in language learning. Korean Journal of Communication \& Disorders, 17, 66-78.

Jin, Y. S., \& Pae, S. (2014). Communication profiles of school-aged children with social communication disorder and high-functioning autism. Communication Sciences \& Disorders, 19, 45-59.

Kim, Y. T. (2014). Assessment and Treatment of Language Disorders in Children (2nd ed.). Seoul: Hakjisa.

Kim, S. E., \& Lee, Y. (2007). Conversation characteristics of children with attention deficit hyperactivity disorder. Communication Sciences \& Disorders, $12,662-675$.

Klusek, J., Martin, G. E., \& Losh, M. (2014). A comparison of pragmatic language in boys with autism and fragile $\mathrm{X}$ syndrome. Journal of Speech, Language, and Hearing Research, 57, 1692-1707.

Kwak, K. C., Oh, S. W., \& Kim, C. T. (2011). Korean-Wechsler Intelligence Scale for Children-IV (K-WISC-IV). Seoul: Hakjisa.

Lee, E. J. (2010). Analysis of abroad pragmatic language measures and assessing instruments. Journal of Speech-Language and Hearing Disorders, 19, 109-132.

Lee, H. J., \& Kim, Y. T. (2001). Turn-taking characteristics of children with specific language impairment and normal children. Korean Journal of Communication \& Disorders, 6, 293-312.

Lee, Y., Heo, H., \& Jang, S. (2015). Language Scale for School-aged Children (LSSC). Seoul: Hakjisa.

Nippold, M. A. (2007). Later language development: school-age children, adolescents, and young adults. Austin, TX: Pro-Ed.

Nippold, M. A., Frantz-Kaspar, M. W., Cramond, P. M., Kirk, C., HaywardMayhew, C., \& MacKinnon, M. (2014). Conversational and narrative speaking in adolescents: examining the use of complex syntax. Journal of Speech, 
Language, and Hearing Research, 57, 876-886.

Norbury, C. F., Nash, M., Baird, G., \& Bishop, D. V. (2004). Using a parental checklist to identify diagnostic groups in children with communication impairment: a validation of the Children's Communication Checklist-2. International Journal of Language \& Communication Disorders, 39, 345364.

O’Neill, D. K. (2007). The language use inventory for young children: a parentreport measure of pragmatic language development for 18-to 47-month-old children. Journal of Speech, Language, and Hearing Research, 50, 214-228.

Oh, S., Lee, E. J., \& Kim, Y. T. (2012). Preliminary study on developing test items of children's pragmatic language checklist. Journal of Speech \& Hearing Disorders, 21, 111-135.

Paul, R. (2007). Language disorders from infancy through adolescence: assessment \& intervention (3rd ed.). St. Louise, MO: Mosby.

Paul, R., Orloski, S. M., Marcinko, H. C., Volmar, F. (2009). Conversational behaviors in youth with high-functioning ASD and Asperger syndrome. Journal of Developmental Disorders, 39, 115-125.
Seo, Y. K., \& Ahn, S. W. (2015). A feasibility study of CCC-2 as a screening instrument for children with communication disorders. Journal of SpeechLanguage \& Hearing Disorders, 24, 319-332.

Song, S., Kim, Y. T., Lee, S., \& Kim, J. A. (2017). Pragmatic language development and correlation with vocabulary ability of 4 -to 10 -year-old typically developing Korean children using audio-visual discourse tasks. Communication Sciences \& Disorders, 22, 218-232.

Song, S. H., Yang, Y. H., \& Kim, Y. T. (2016). A meta-analysis of Children's Communication Checklist (CCC) for children \& adolescents with pragmatic language impairment. Communication Sciences \& Disorders, 21, 436450 .

Verté, S., Geurts, H. M., Roeyers, H., Rosseel, Y., Oosterlaan, J., \& Sergeant, J. A. (2006). Can the Children's Communication Checklist differentiate autism spectrum subtypes? Autism, 10, 266-287.

Yoon, H. R., \& Lee, J. H. (2007). Theory and practice of small-group language therapy. Seoul: Seoul Community Rehabilitation Center. 


\section{국문초록}

\section{아동화용언어체크리스트(CPLC)와 대화관찰 간 상관 연구}

오소정

동명대학교 언어치료학과

배경 및 목적: 본 연구는 학령기 일반 아동 및 화용문제를 가진 언어장애 아동을 대상으로 아동화용언어체크리스트(CPLC)의 타당도 검증을 위하여 실제 대화에서의 대화기술, 의사소통 능력 측정치와 CPLC 결과 간 상관과 대화관찰에서의 두 집단 간 수행 차이가 $\mathrm{CPLC}$ 에서도 드러나는지 살펴봄으로써 CPLC가 실제 대화에서의 화용능력을 잘 반영할 수 있는지 살펴보고자 한다. 방법: 총 28 명의 $1-4$ 학년 학령기 일반 아동 $(\mathrm{N}=14)$ 과 학년과 생활연령일치 화용문제가 보고된 언어장애 아동 $(\mathrm{N}=14)$ 에게 CPLC와 반구조화된 대화 관찰 절차를 실시하여 두 집단 간차이를 살펴보고 CPLC 점수와 대응되는 대화관찰에서의 대화기술 및 의사소통 측정치 간 상관을 구 하였다. 결과: CPLC와 대화관찰 측정치에서 두 집단 간 유의한 차이가 있는지 두 독립표본 $t$-검정으로 살펴본 결과, 대화차례 관리 및 적절/부적절한 주제유지와 개시 등에서 집단 간 유의미한 차이가 있었으며 CPLC 점수에서는 모든 하위점수와 총점에서 집단 간 차이 가 있었다. CPLC 점수와 대화 측정치 간 상관은 $40-60$ 정도로 중간 정도의 상관을 나타냈다. 논의 및 결론: CPLC는 실제 대화에서의 의사소통 능력, 대화기술을 어느 정도 반영한다고 할 수 있으며 화용언어평가도구들은 서로 상관관계의 정도나 집단 간 차이를 가져오 는 변수들이 다르므로 보다 확실한 임상적 유용성 검증을 위해서는 화용평가도구 간, 다른 평가와의 상관연구와 함께 장애 아동을 대 상으로 한 민감도, 특이도 연구가 필요하다.

핵심어: 화용언어, 체크리스트, 대화 기술, 학령기 아동, 대화 관찰 측정치

이 논문은 2014년도 정부(교육부)의 재원으로 한국연구재단의 지원을 받아 연구되었음(No. NRF-2014S1A5A8018878).

\section{참고문헌}

곽금주, 오상우, 김청택(2011). 한국판 웩슬러 아동용 지능검사(K-WISC-IV). 서울: 학지사.

김성은, 이윤경(2007). 주의력결핍 과잉행동장애(ADHD) 아동의 말차례 주고받기 특성, 언어청각장애연구, 12, 662-675.

김영태(2014). 아동언어장애의 진단 및 치료(제2판). 서울: 학지사.

서유경, 안성우(2015). 의사소통장애 선별도구로서 CCC-2의 유용성. 언어치료연구, 24, 319-332.

송승하, 김영태, 이수정, 김정아(2017). 시청각적 담화 과제를 활용한 4-10세 아동의 화용언어 발달 및 어휘능력과의 상관도 연구. 언어청각장애연구,

22, 218-232.

송승하, 양윤희, 김영태, 임동선(2016). 아동 의사소통 체크리스트(CCC)를 활용한 화용언어장애아동의 의사소통능력 평가에 대한 메타분석. 언어

청각장애연구, 21, 436-450.

윤혜련, 이지희(2007). 소그룹 언어치료의 이론과 실제. 서울: 서울장애인종합복지관.

이윤경, 허현숙, 장승민(2015). 학령기 아동 언어검사. 서울: 학지사.

이은주(2010). 국외 화용언어 평가 도구 분석. 언어치료연구, 19, 109-132.

이효진, 김영태(2001). 단순언어장애 아동의 대화 말차례 특성. 언어청각장애연구, 6, 293-312.

진연선, 배소영(2014). 학령기 사회적의사소통장애와 고기능자폐 아동의 의사소통 능력 차이. 언어청각장애연구, 19, 45-59.

최지은, 이윤경(2013). 학령기 고기능 자폐범주성장애 아동의 대화차례 주고받기 및 주제운용능력. 언어청각장애연구, 18, 12-23.

최지은, 이윤경(2015). 학령기 고기능 자폐스펙트럼장애 아동의 주제유지능력: 수반성과 정보성을 중심으로. 언어청각장애연구, 20, 413-423.

허현숙, 이윤경(2012). 언어학습부진아동의 대화차례 주고받기 및 주제운용 특성. 언어청각장애연구, 17, 66-78. 